Copyright (C1996, American Institute of Aeronautics and Astronautics, Inc.

AIAA Meeting Papers on Disc, July 1996

A9636945, AIAA Paper 96-2712

\title{
Ionic and neutral particle transport property measurements in the plume of an SPT-100
}

\author{
Lyon B. King \\ Michigan Univ., Ann Arbor
}

Alec D. Gallimore

Michigan Univ., Ann Arbor

\begin{abstract}
AIAA, ASME, SAE, and ASEE, Joint Propulsion Conference and Exhibit, 32nd, Lake Buena Vista, FL, July 1-3, 1996
\end{abstract}

In order to understand the interaction between the SPT-100 thruster and the spacecraft, accurate knowledge of the exhaust plume properties must be obtained. This investigation utilized a suite of interrelated diagnostic probes in an effort to provide detailed knowledge of the exhaust plume on a molecular-kinetic level. Probes used for the investigation included a Retarding Potential Analyzer (RPA), a planar Faraday probe, both total and radiant heat-flux probes, as well as a newly developed Neutral Particle Flux probe. Combining the knowledge gained from these probes, it was possible to quantify the transport of mass, energy, and charge within the plume at 0.5 - and $1.0-\mathrm{m}$ radii from the thruster exit. Among the phenomena uncovered were a high-energy ionic annulus surrounding a narrow low-energy core within the plume at $0.5 \mathrm{~m}$. This core was still incompletely filled in at 1.0 -m radius. Additionally, a population of energetic charge exchange neutrals was found along with the corresponding low-energy charge exchange ions, due to plume/background gas interactions. (Author) 


\title{
Ionic and Neutral Particle Transport Property Measurements in the Plume of an SPT-100
}

\author{
Lyon B. King and Alec D. Gallimore \\ Plasmadynamics and Electric Propulsion Laboratory \\ Department of Aerospace Engineering \\ University of Michigan \\ Ann Arbor, MI USA
}

\begin{abstract}
$\underline{\text { Abstract }}$
In order to understand the interaction between the SPT-100 thruster and the spacecraft accurate knowledge of exhaust plume properties must be obtained. This investigation utilized a suite of inter-related diagnostic probes in an effort to provide detailed knowledge of the exhaust plume on a molecular kinetic level. Probes used for the investigation included a Retarding Potential Analyzer, (RPA), a planar Faraday probe, both total and radiant heat flux probes, as well as a newly developed Neutral Particle Flux probe. Combining knowledge gained from these probes it was possible to quantify the transport of mass, energy, and charge within the plume at $0.5 \mathrm{~m}$ and $1.0 \mathrm{~m}$ radius from thruster exit. Among the phenomena uncovered were a high energy ionic annulus surrounding a narrow low energy core within the plume at $0.5 \mathrm{~m}$. This core was still incompletely filled in at $1.0 \mathrm{~m}$ radius. Additionally, a population of energetic charge exchange neutrals was found along with the corresponding low energy charge exchange ions due to plume/background gas interactions.
\end{abstract}

\section{Nomenclature}

$\begin{array}{ll}A_{\text {probe }} & =\text { Area of RPA collector }\left(\mathrm{m}^{2}\right) \\ \mathrm{e} & =\text { Elementary charge (coul) } \\ \mathrm{f} & \text { =Velocity distribution function } \\ \mathrm{g} & =\text { Relative interparticle speed }(\mathrm{m} / \mathrm{s}) \\ \mathrm{I} & =\text { Current }(\mathrm{A}) \\ \mathrm{J}_{\mathrm{i}} & =\text { Ion current density }\left(\mathrm{A} / \mathrm{m}^{2}\right) \\ \mathrm{k} & =\text { Boltzmann Constant } \\ \mathrm{k}_{\mathrm{C}} & =\text { Coefficient of Thermal Conduction } \\ \mathrm{m}_{\mathrm{i}} & =\text { Mass of ion }(\mathrm{kg}) \\ \mathrm{m}_{\mathrm{n}} & =\text { Mass of neutral }(\mathrm{kg}) \\ \mathrm{N}_{\mathrm{i}, 0} & =\text { Rate of CEX production }\left(\mathrm{m}^{-3} \mathrm{~s}^{-1}\right) \\ \mathrm{n}_{\mathrm{i}} & =\text { Density of ions }\left(\mathrm{m}^{-3}\right) \\ \mathrm{n}_{\mathrm{n}} & =\text { Density of fast neutrals }\left(\mathrm{m}^{-3}\right) \\ \mathrm{n}_{0} & =\text { Density of slow neutrals }\left(\mathrm{m}^{-3}\right) \\ \mathrm{n}_{\mathrm{m}} & =\text { Measured den. of neutrals }\left(\mathrm{m}^{-3}\right) \\ \mathrm{q} & =\text { Heat Flux }\left(\mathrm{W} / \mathrm{m}^{2}\right) \\ \mathrm{q}_{\text {conv }} & =\text { Convective Heat Flux }\left(\mathrm{W} / \mathrm{m}^{2}\right) \\ \mathrm{T} & =\text { Temperature }(\mathrm{K})\end{array}$

$\begin{array}{ll}\mathrm{T}_{\mathrm{m}} & =\text { Measured temp of neutrals }(\mathrm{K}) \\ \mathrm{T}_{\mathrm{n}} & =\text { Temp of fast neutrals }(\mathrm{K}) \\ \mathrm{T}_{0} & =\text { Temp of slow neutrals }(\mathrm{K}) \\ \mathrm{T}_{\mathrm{p}} & =\text { Temp of probe surface }(\mathrm{K}) \\ \mathrm{t} & =\text { Thickness of plate }(\mathrm{m}) \\ \mathrm{u}_{\mathrm{i}} & =\text { Velocity of ions }(\mathrm{m} / \mathrm{s}) \\ \mathrm{u}_{\mathrm{m}} & =\text { Vel. of measured neutrals }(\mathrm{m} / \mathrm{s}) \\ \mathrm{u}_{\mathrm{n}} & \text { =Velocity of fast neutrals }(\mathrm{m} / \mathrm{s}) \\ \mathrm{u}_{0} & \text { =Velocity of slow neutrals }(\mathrm{m} / \mathrm{s}) \\ \mathrm{V} & =\text { Voltage of lon Repeller }(\mathrm{V}) \\ \bar{v}_{0} & =\text { Ave slow neutral speed }(\mathrm{m} / \mathrm{s}) \\ \Phi_{\mathrm{i}}(\mathrm{m}) & =\text { Incident flux of quantity "m" } \\ \Phi_{\mathrm{r}}(\mathrm{m}) & =\text { Reflected flux of quantity "m" } \\ \sigma_{\mathrm{C}} & =\text { Total Cross Sec. for CEX }\left(\mathrm{m}^{2}\right) \\ <\mathrm{x}> & =\text { Average value of quantity } \mathrm{x}\end{array}$

\section{Introduction}

In an effort to fully flight-qualify the SPT-100 for use in satellite missions much research has focused on lifetime and

Copyright 1996 by the American Institute of Aeronautics and Astronautics, Inc. All rights reserved. 
performance issues of the thruster. As a result the baseline operating conditions of the SPT100 are now well established. The next hurtle to widespread use of these devices is an understanding of thruster/spacecraft interaction phenomena. The thruster may interact with the spacecraft through three fundamental processes: thruster-generated electromagnetic interference (EMI), particle impingement from the exhaust plume, or radiative heating of spacecraft components. EMI may interfere with communication signals and instrument performance, while particle impingement and radiant heating may cause physical damage to spacecraft hardware.

The exhaust plume of an SPT-100 consists mainly of high energy (around 200-300V) xenon ions produced and accelerated within the thruster. However, there are additional plume components due to parasitic facility effects (during ground testing) and secondary ion processes occurring in the acceleration zone of the thruster. These additional components include slow propellant ions as well as both slow and fast neutral atoms.

The neutral and ionic portions of the plasma flow are linked through the process of resonant charge exchange (CEX). In this process a high energy ion collides with a low energy neutral of the same species. This collision causes the transfer of an electron from the slow atom to the fast ion. The net result is a slow ion and fast neutral atom. In equation form this can be represented as

$$
\mathrm{Xe}^{+}+\mathrm{Xe} \rightarrow \mathrm{Xe}+\mathrm{Xe}^{+}
$$

where bold face is used to indicate the high energy particle. The process is termed to be resonant since the energy liberated by the electron-ion recombination is equal to the first ionization potential of the neutral; no third body is required. This process can occur within the thruster acceleration region due to entrained ambient background gas or unionized propellant, or it can occur downstream of the acceleration zone due to ambient background gas. There are basically two approaches that can be used to detect CEX: one can either look for the slow ion products or the fast neutral products since their production rates are one-to-one.

The ionic portion of the plume, both high and low energy, can be detected in a straightforward manner through the use of classical electrostatic-type plasma probes. However, the neutral component of the exhaust is transparent to these electric probes. A new diagnostic technique was developed for this research that allowed analysis of the neutral component of the plasma. 1

The objective of this investigation was to fully characterize the particle properties of the SPT-100 plume. This was accomplished by making measurements over an extensive volume of the plume using a suite of interrelated diagnostic probes.

\section{Description of Probes}

This section presents a discussion of the basic theory behind the probes utilized in this investigation. In addition, details of probe hardware construction and design are documented.

RPA. The most fundamental quantity from a gaskinetic standpoint for any flow is the velocity distribution function of the flow constituents. This function, when combined with the particle density, can be theoretically used to calculate any flow property of interest.

For this investigation a gridded Retarding Potential Analyzer (RPA) was used to determine the ion energy distribution in the plume. This well known technique ${ }^{2}$ uses an electrostatic grid to selectively retard all ions with energies below a certain threshold. A schematic of the RPA used in this investigation is shown as Figure 1. This RPA employs three grids: the first grid along with the probe body are allowed to float, the second grid is biased at a constant negative potential to repel all plasma electron current from the collector, the third grid is the ion retarding grid. This grid is connected to a variable high voltage power supply. The 
potential of this grid is adjusted from zero to $500 \mathrm{~V}$ to selectively repel ion current from the collector. The probe body, grids, and collector were fashioned from stainless steel. The insulators between grids were made of Teflon and ceramic. The entire probe was approximately $2.5 \mathrm{~cm}$ in diameter. The grid mesh sizes are as follows. Floating grid: $.112 \mathrm{~mm}$ dia. wire spaced at $.266 \mathrm{~mm}$ centers; electron retarding grid: $.028 \mathrm{~mm}$ dia. wire spaced at $.056 \mathrm{~mm}$ centers; and ion retarding grid: $.042 \mathrm{~mm}$ dia. wire spaced at $.225 \mathrm{~mm}$ centers. For a more detailed description of RPA Parameters refer to reference [3].

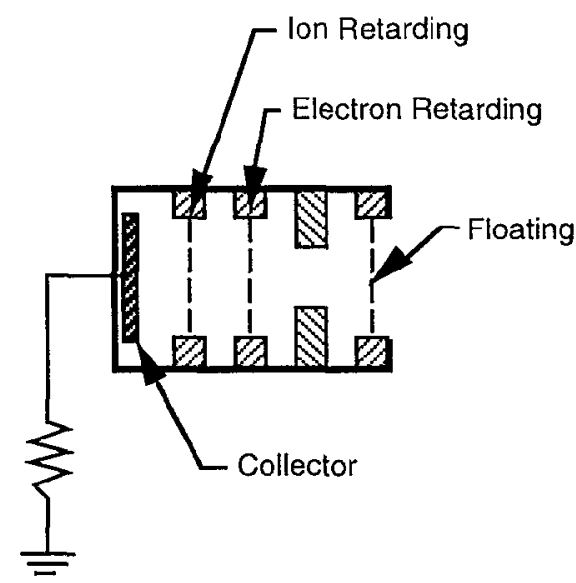

Figure 1. Schematic of RPA grid configuration.

The collected ion current is given by

$$
I=A_{\text {probe }} e_{i} \int_{v_{\min }}^{\infty} u_{i} f\left(u_{i}\right) d u_{i}
$$

where $u_{i}$ is the ion velocity, $n_{i}$ is the ion density, Aprobe is the surface area of the probe collector, $\mathrm{v}_{\mathrm{min}}$ is the lowest ion velocity capable of passing through the repelling grid, and $f\left(u_{i}\right)$ is the ion velocity distribution function. Putting this equation in terms of ion potential energy (volts) yields

$$
I(V)=\frac{e^{2} n_{i} A_{\text {probe }}}{m_{i}} \int_{V}^{\infty} f\left(V^{\prime}\right) d V^{\prime}
$$

In this equation $V$ is the voltage of the ion repelling grid and $\mathrm{m}_{\mathrm{i}}$ is the mass of the ion. By varying the ion repelling voltage, data is obtained as $I(V)$ vs V. Differentiating equation (1) it is easily shown that

$$
-\frac{d I}{d V}=\frac{e^{2} n_{i} A_{\text {probe }}}{m_{i}} f(V) .
$$

Therefore the negative derivative of the $\mathrm{I}(\mathrm{V})$ vs $\mathrm{V}$ data is directly proportional to the ion energy distribution function.

Faraday Probe. The Faraday probe is essentially a $2.3 \mathrm{~cm}$ diameter planar disk coated with tungsten. The tungsten is used to provide a very low secondary electron yield due to impacting ions. This disk is surrounded by a cylindrical body that ensures a uniform electric field over the face of the collecting disk, eliminating edge effects. The collector and body of the Faraday probe are biased with a negative voltage of sufficient strength to repel all plasma electron current while collecting only plasma ion current. A schematic of the probe is shown as Figure 2.

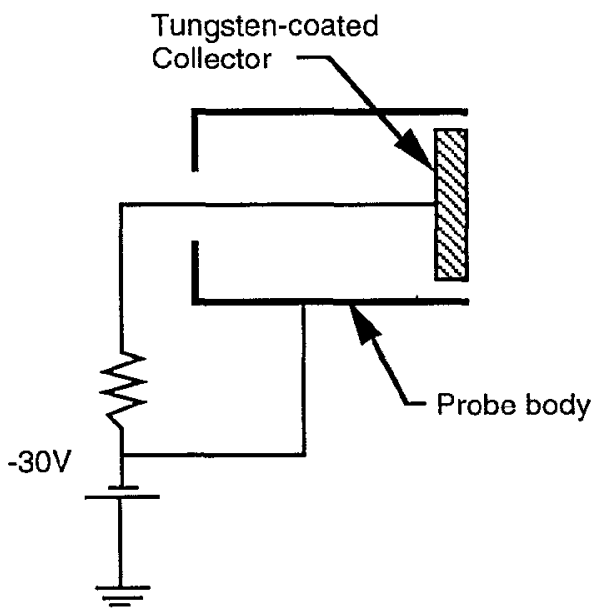

Figure 2. Schematic of Faraday Probe.

The Faraday probe directly measures the first moment of the ion energy distribution function, namely ion current density, $\mathrm{J}_{\mathrm{i}}$ :

$$
J_{i}=e_{i} \int_{0}^{\infty} u_{i} f\left(u_{i}\right) d u_{i}
$$


By combining this direct measurement of $\mathrm{J}_{\mathrm{i}}$ with the RPA-measured $f\left(u_{i}\right)$, the ion number density can be obtained as

$$
\mathrm{n}_{\mathrm{i}}=\frac{\mathrm{J}_{\mathrm{i}}}{\mathrm{e}\left\langle\mathrm{u}_{\mathrm{i}}\right\rangle}
$$

Heat Flux Probe. The particle convective heat flux, or power density, is given by the third moment of the distribution function.

$$
\Phi_{i}^{\left(\frac{1}{2} m u_{i}^{2}\right)}=\frac{1}{2} m_{i} n_{i} \int_{0}^{\infty} u_{i}^{3} f\left(u_{i}\right) d u_{i}
$$

Where $\Phi_{i} \mathrm{~m}$ denotes the incident flux of quantity $\mathrm{m}$. Since there are no internal degrees of freedom for $\mathrm{X} e$, the convective heat flux to a surface immersed in the plume is given by the difference between the incident heat flux, equation (5), and the heat flux reflected from the surface,

$$
\Phi_{r}^{\left(\frac{1}{2} m u_{i}^{2}\right)}=2 k T_{p} n_{i} \int_{0}^{\infty} u_{i} f\left(u_{i}\right) d u_{i}
$$

In equation (6) $\Phi_{\mathrm{r}}^{\mathrm{m}}$ denotes the reflected flux of quantity $m, k$ is Boltzmann's constant, and $\mathrm{T}_{\mathrm{p}}$ is the temperature of the probe.

A heat flux probe was used to measure the third moment of the distribution function. The transducer for this probe was manufactured by the Medtherm corporation. This transducer was a Schmidt-Boelter thermopile type device; in such a device the flat surface of a plate is exposed to a heat source. The heat is then conducted in a direction normal to the exposed surface through the plate. The heat flux, $q$, to the face is then given by

$$
\mathrm{q}=\mathrm{k}_{\mathrm{c}} \frac{\Delta \mathrm{T}}{\mathrm{t}}
$$

where $k_{c}$ is the coefficient of thermal conduction for the plate, $\Delta \mathrm{T}$ is the temperature difference between the front and rear face of the plate, and $t$ is the plate thickness.
The probe is shown in Figure 3. The probe consisted of a water cooled housing containing dual Schmidt-Boelter transducers. The transducer housing was instrumented with a thermocouple to provide a measurement of probe surface temperature. Each transducer was coated with optical black to provide known absortivity. One transducer was exposed directly to the environment to obtain a measure of total heat flux. The second identical transducer was covered with a sapphire window. This window shielded the device from convective heat flux, while being transparent to radiant heat flux. By subtracting the measured radiant heat flux from the measured total heat flux an accurate value of particle convective heating can be obtained. Calibration of these transducers was performed by the manufacturer to NISTtraceable standards.

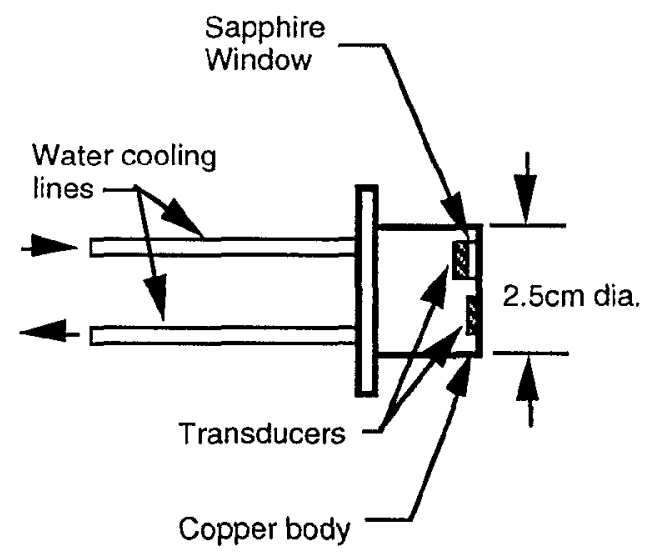

Figure 3. Schematic of Heat Flux Probe showing both radiant and total heat flux transducers.

The convective heat flux to such a probe is given as the difference between equation (6) and equation (5), namely

Equation [7]:

$q_{\text {conv }}=n_{i}\left[\frac{1}{2} m_{i} \int_{0}^{\infty} u_{i}^{3} f\left(u_{i}\right) d u_{i}-2 k T_{p} \int_{0}^{\infty} u_{i} f\left(u_{i}\right) d u_{i}\right]$

It is easily seen from equation (7) that a direct measurement of qconv combined with knowledge of the first and third moments of the ion distribution function and the probe 
body temperature, $T_{p}$, can be used to solve for the ion density, $\mathrm{n}_{\mathbf{i}}$.

An important note to be made is that the heat flux probe employs no retarding electrostatic fields, nor does it rely on chargecarrying particles for detection. Therefore, even though equations (5) through (7) are written solely in terms of ion properties, the measured convective heat flux is actually due to both ions and neutral particles. It is possible (as will be shown later in the Analysis of Results section) to gain information about the neutral atom component by comparing the heat fluxderived ion density to the Faraday probederived ion density.

NPF Probe. In an attempt to characterize the neutral particle component of the plasma flow a new probe design was implemented. This probe is referred to as a Neutral Particle Flux probe (NPF). Detailed documentation of this design is presented elsewhere, ${ }^{1}$ however an overview of the probe operation will be presented here.

The probe is essentially a hybrid between an RPA and a vacuum pressure gauge. A set of electrostatic grids are mounted to the inlet of a hot cathode ionization gauge tube. By using one grid as an electron retarding grid and setting another grid to a high positive voltage to repel all ion flux from the tube, only the neutral component of the plasma is permitted to enter the tube. This neutral gas is ionized and sensed in the standard method of hot cathode ionization gauges. The gauge output is monitored on a standard hot cathode ionization gauge controller calibrated for $\mathrm{Xe}$ in units of torr. A schematic of the NPF probe is shown as Figure 4.

The comprehensive theory for interpretation of probe data is presented in a separate paper also presented at this conference. 1 Briefly, the pressure measured inside the ionization gauge tube is determined by the condition that the neutral particle flux entering the probe must be equal to the neutral particle flux exiting the probe. Specifically,

$$
\mathrm{n}_{\mathrm{n}}\left\langle\mathrm{u}_{\mathrm{n}}\right\rangle_{\text {in }}=\mathrm{n}_{\mathrm{m}}\left\langle\mathrm{u}_{\mathrm{m}}\right\rangle_{\text {out }}
$$

In equation (8) quantities with a subscript $n$ denote neutral particle properties within the plume, while quantities with a subscript $m$ denote neutral particle properties within the measurement volume (gauge tube). Using free molecular theory to calculate the escape flux from the ion gauge tube yields

$$
\mathrm{n}_{\mathrm{m}}\left\langle\mathrm{u}_{\mathrm{m}}\right\rangle_{\text {out }}=\mathrm{n}_{\mathrm{m}} \sqrt{\frac{\mathrm{kT} \mathrm{m}}{2 \pi \mathrm{m}}}
$$

Utilizing the ideal gas law to express $n_{m}$ in terms of measured pressure, $P_{m}$ and inserting this result into equation (8) yields the relationship between probe-measured pressure and neutral particle flux into the probe:

$$
\mathrm{n}_{\mathrm{n}}\left\langle\mathrm{u}_{\mathrm{n}}\right\rangle_{\mathrm{in}}=\frac{\mathrm{P}_{\mathrm{m}}}{\sqrt{2 \pi \mathrm{mkT}}}
$$

It is apparent, then, that the pressure measured within the probe ionization gauge at a constant gauge temperature is directly proportional to the flux of neutral particles in the plume.

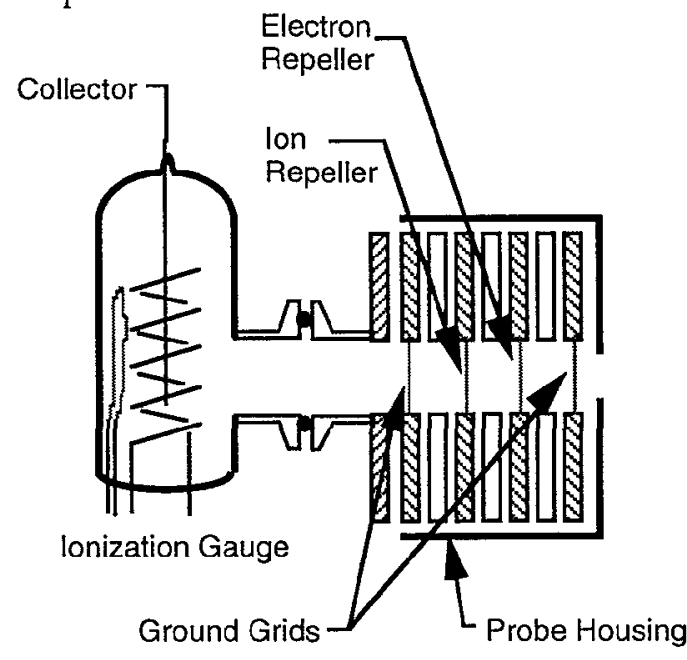

Figure 4. Schematic of NPF Probe.

\section{Experimental Set-up}

This section presents the overall experimental set-up including pertinent parameters and test procedures. 
Facility. All experimental tests were performed in the University of Michigan's Plasmadynamics and Electric Propulsion Laboratory (PEPL). The centerpiece of this laboratory is a large $6 \mathrm{~m}$ dia. by $9 \mathrm{~m}$ long vacuum chamber capable of base pressures of approximately $2 \times 10^{-5}$ torr. A detailed description of this facility has been published previously. ${ }^{4}$

SPT-100. The thruster used for this experiment was a Fakel flight model SPT100. The thruster was controlled by a Space Systems/Loral power processing unit (PPU). Nominal operating conditions were utilized: discharge voltage $=300 \mathrm{~V}$, discharge current $=4.5 \mathrm{~A}$, total flow rate of $56 \mathrm{SCCM}$ of Xe with a $10 \%$ cathode split. Tank pressure was maintained at less than $5 \times 10^{-5}$ torr true Xe pressure during all testing as determined by two hot cathode ionization gauges.

Probes. The Faraday probe body, collector and the RPA electron retarding grid were biased approximately $-30 \mathrm{~V}$ with respect to thruster cathode potential. This voltage was sufficient to repel all plasma electrons while attracting only ion current. 5 The RPA ion retarding grid was adjustable from 0 to approximately $500 \mathrm{~V}$.

The heat flux probe water cooling lines were connected to a closed-loop thermostatically controlled refrigeration system. The probe body maintained a temperature of between 5 and $6 \operatorname{deg} C$ for all test points.

The NPF probe electron retarding grid was also set at $-30 \mathrm{~V}$ with respect to thruster cathode potential. The ion retarding grid of the NPF was set to a constant value of about $500 \mathrm{~V}$. This value, as determined from an RPA-type trace of probe output, was sufficient to repel all plume ions. ${ }^{1}$

Test Set-up. All three probes were mounted simultaneously to a rotating boom apparatus on a remote positioning system. An overview of the set up is shown as Figure 5.
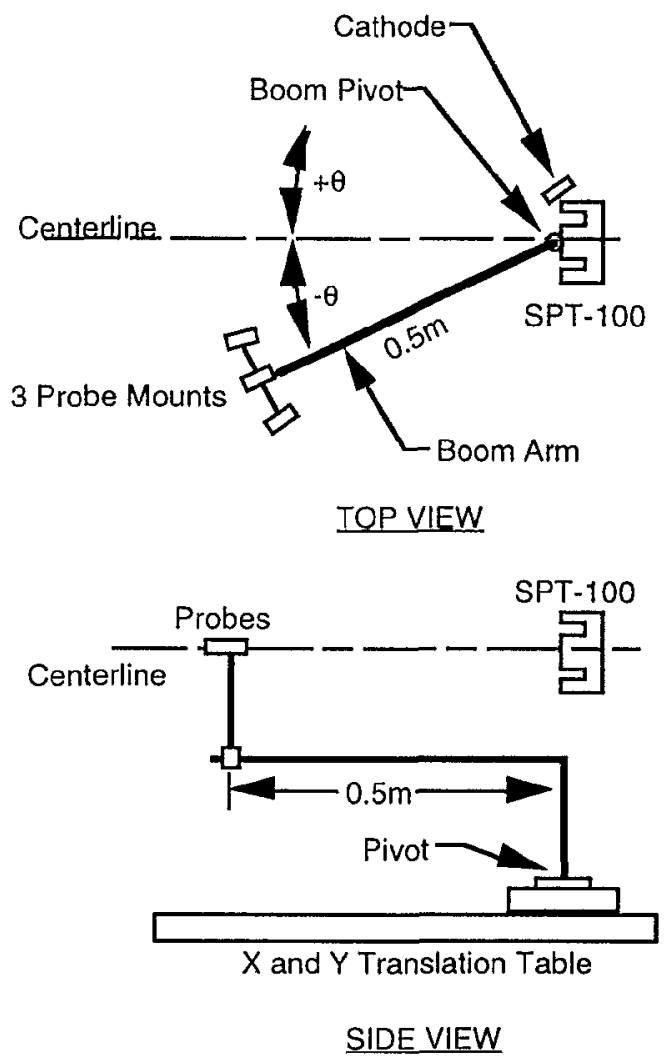

Figure 5. Experimental set-up showing boom/table/thruster layout.

The instruments were positioned $0.5 \mathrm{~m}$ from the boom pivot point. By positioning the pivot point directly under the thruster exit plane it was possible to obtain probe data at various angles off thruster centerline at a constant radial distance of $0.5 \mathrm{~m}$ by simply rotating the boom. As indicated in Figure 5, positive angles off centerline indicate measurements taken on the cathode side of the thruster, while negative angles denote the non-cathode half plane. This convention will be followed throughout the paper. In this configuration heat flux probe data was obtained over a range of -60 deg to $60 \mathrm{deg}$ from thruster centerline, at $2 \mathrm{deg}$ increments. At the same time an independent investigation was conducted using the Faraday probe. ${ }^{6}$ Faraday data was obtained simultaneously at 5 deg increments from -60 to 60 deg; this data will be referenced throughout this paper. Unfortunately, due to positioning equipment complications late in the test it was only possible to obtain RPA 
and NPF sensor data in the negative half plane from -60 deg to centerline (non-cathode side) at $5 \mathrm{deg}$ and $2 \mathrm{deg}$ increments, respectively.

By translating the pivot point of the instrument boom, data was then collected at radial positions of $1 \mathrm{~m}$ from the thruster exit plane at 5 deg. increments for the heat flux sensor and 10 deg. increments for the RPA. Again, due to equipment complications the heat flux data was limited to the half plane from 0 to $60 \mathrm{deg}$ (cathode side), the RPA data was limited to -60 to 0 deg, and the Faraday data was omitted due to probe malfunction.

Upon completion of the baseline data set the probe configuration was changed and the Faraday probe was repaired. In order to quantify the background ambient plasma conditions separately from the direct plume flux the Faraday probe was turned "backward." In this position the collecting surface of the probe remained at $0.5 \mathrm{~m}$ radius from the thruster exit plane, however the probe faced directly away from the thruster. This allowed the probe body to shield the collecting surface from the direct plume flux, creating a quiet wake. By sampling the plasma properties within this wake it was possible to directly measure the ambient background plasma conditions due to chamber pumping limitations and CEX. This data was obtained for the Faraday probe at $0.5 \mathrm{~m}$ from -60 to 60 deg at 2 deg increments, and at $1 \mathrm{~m}$ from -60 to $60 \mathrm{deg}$ at $5 \mathrm{deg}$ increments.

\section{$\underline{\text { Results }}$}

This section of the paper presents the unprocessed probe data. For analysis of this data see Analysis of Results.

\section{$0.5 \mathrm{~m}$ Radius Data}

RPA. Very smooth current vs. ion repelling voltage characteristics were obtained for all RPA data points. These results are shown as Figures 6.

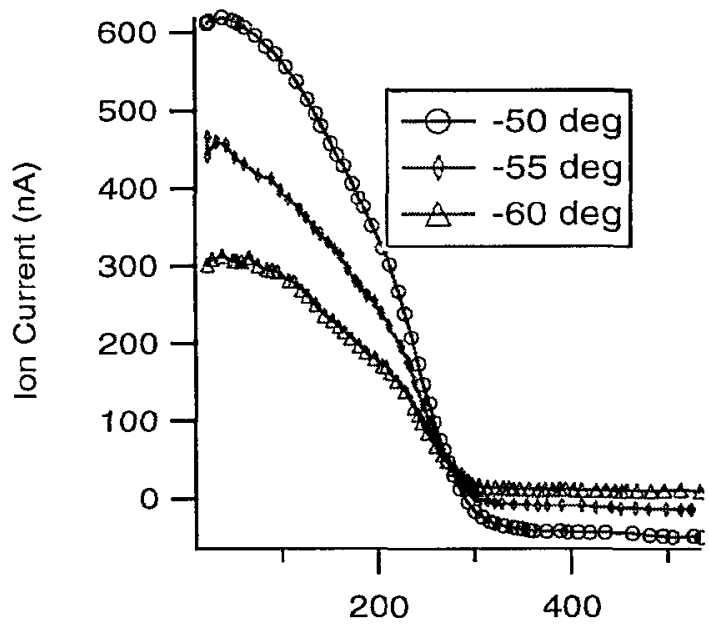

Ion Retarding Potential (V)

Figure 6a. RPA current characteristic curves at $0.5 \mathrm{~m}$ radius from thruster for angles of $-60,-55$, and $-50 \mathrm{deg}$. off thruster centerline.

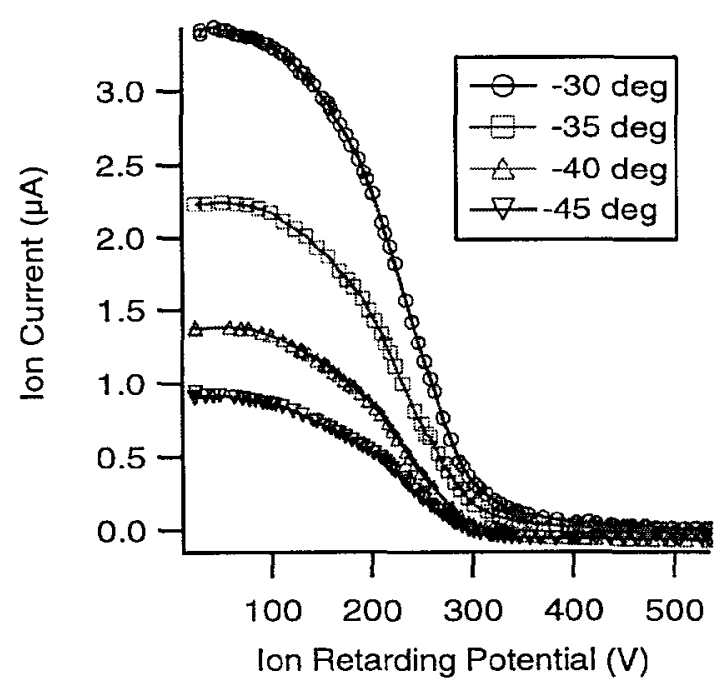

Figure 6b. RPA current characteristic curves at $0.5 \mathrm{~m}$ radius from thruster for angles of $-45,-40$, -35 , and $-30 \mathrm{deg}$. off thruster centerline. 


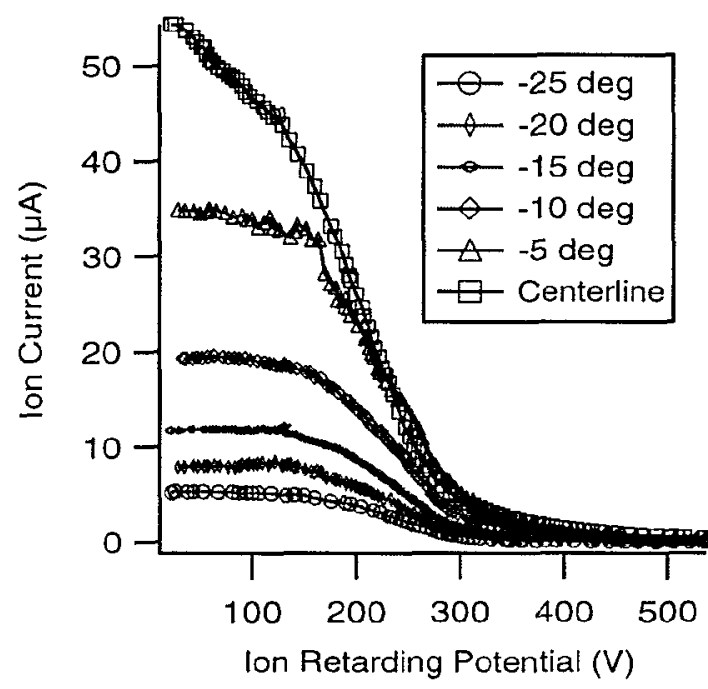

Figure 6c. RPA current characteristic curves at $0.5 \mathrm{~m}$ radius from thruster for angles of $-25,-20$, $-15,-10,-5$, and 0 deg. off thruster centerline.

Faraday Probe. Because of time constraints the Faraday probe data at $0.5 \mathrm{~m}$ facing into the plume was obtained as part of an independently sponsored program, however the test was run simultaneously with this investigation. 6 This data is shown as Figure 7. Overlaid on this plot is the data obtained with the Faraday probe facing away from the thruster sampling the ambient wake plasma.

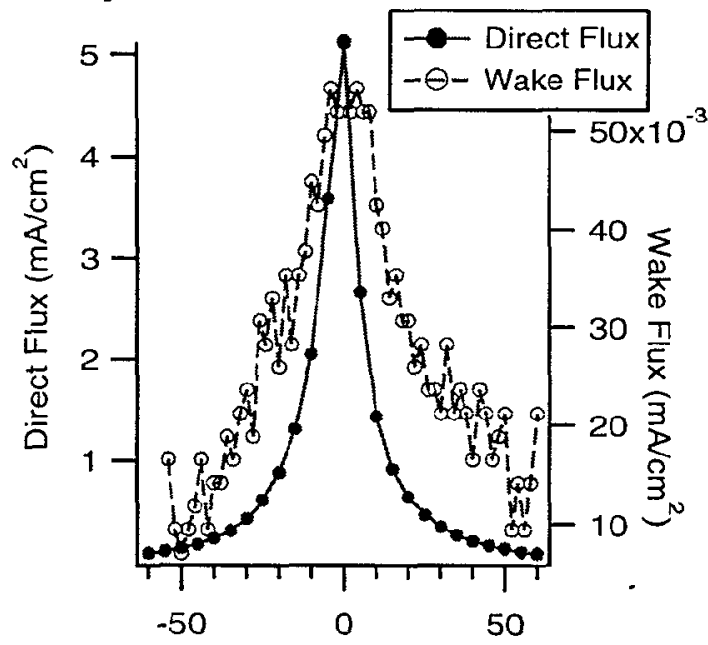

Angle off Thruster Centerline (deg)

Figure 7. Faraday probe-measured ion current density at $0.5 \mathrm{~m}$ radius from thruster exit. Data is shown for both direct plume impingement ${ }^{6}$ and for ambient wake current density.
Heat Flux Probe. Data was obtained with the heat flux probe at $2 \mathrm{deg}$ increments from $-60 \mathrm{deg}$ to $60 \mathrm{deg}$ at $0.5 \mathrm{~m}$ radius from thruster exit. Both total heat flux and radiant heat flux were recorded by separate transducers located within $5 \mathrm{~mm}$ of each other. For the positions of $-2,0$, and 2 deg the measured total heat flux exceeded the calibrated range of the sensor. Total heat flux data is therefore unavailable for these points. This data is shown as Figure 8.

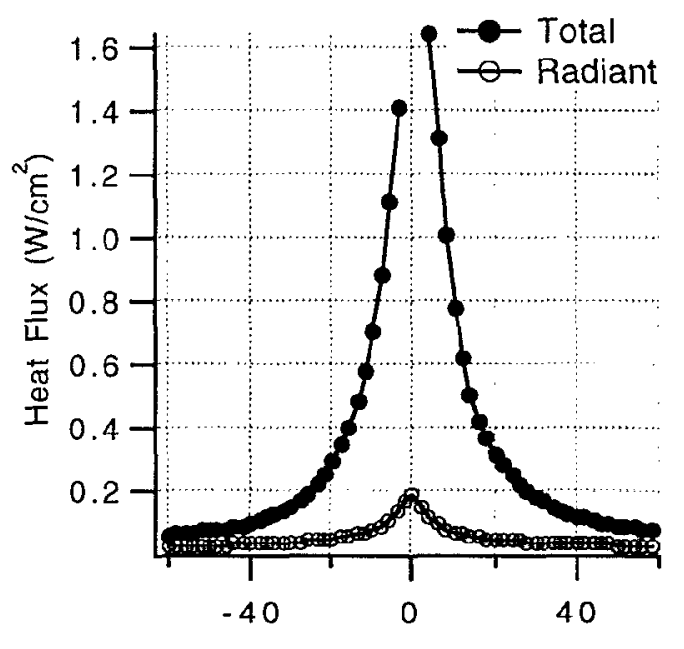

Angle off Thruster Centerline (deg)

Figure 8. Total and Radiant heat flux at $0.5 \mathrm{~m}$ radius from thruster exit plane.

NPF Probe. The NPF probe data was obtained at 2 deg increments in the half plane from -60 deg to 0 deg (non-cathode side) from thruster centerline. The overpressure protect set point for the hot cathode tube was about 6 mTorr. At this pressure, the tube deenergized in order to prevent damage to the filament. Because of this, data within $10 \mathrm{deg}$ of centerline could not be obtained. The data is shown in Figure 9. 


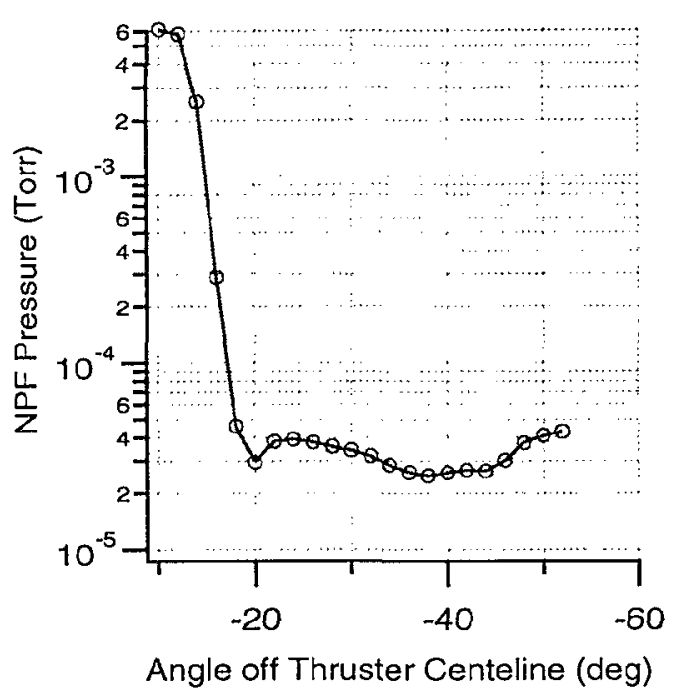

Figure 9. NPF Sensor ion gauge output at $0.5 \mathrm{~m}$ radius from thruster exit plane.

\section{0 m Radius Data}

RPA. Data was obtained with the RPA for the half plane from -60 deg to 0 deg off thruster centerline at $10 \mathrm{deg}$ increments. All traces again showed smooth current/voltage characteristics. This data is shown in Figures 10.

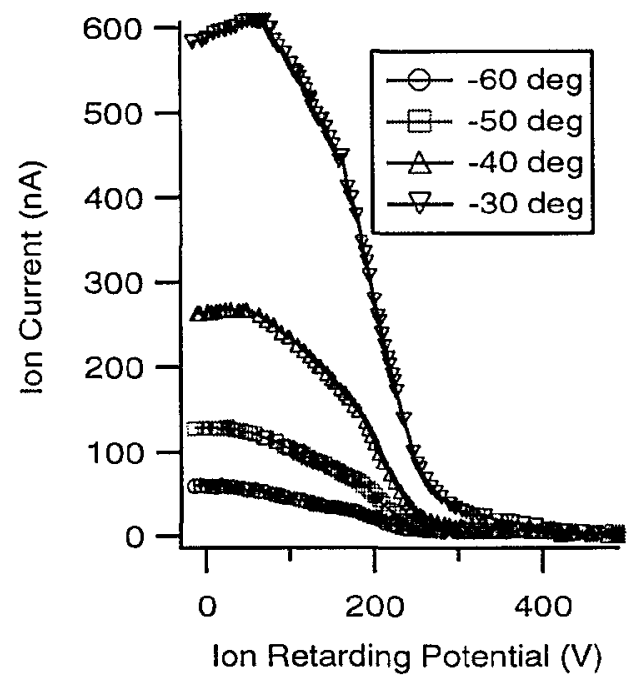

Figure 10a. RPA current characteristic curves at $1.0 \mathrm{~m}$ radius from thruster for positions $-60,-50$, 40 , and -30 deg off thruster centerline.

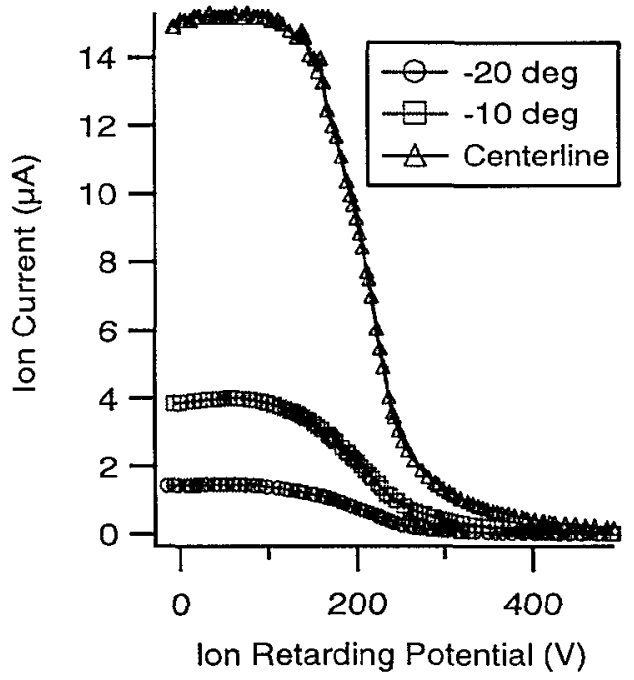

Figure 10b. RPA current characteristic curves at $\mathbf{1 . 0 m}$ radius from thruster for positions $-20,-10$, and 0 deg. off thruster centerline.

Faraday Probe. Due to probe malfunction on one of the testing days Faraday probe data at $1.0 \mathrm{~m}$ radius from thruster facing into plume was not obtained. However, probe data facing away from the thruster at $1.0 \mathrm{~m}$ radius was obtained providing a sample of the ambient plasma wake at this distance. This data is shown as Figure 11.

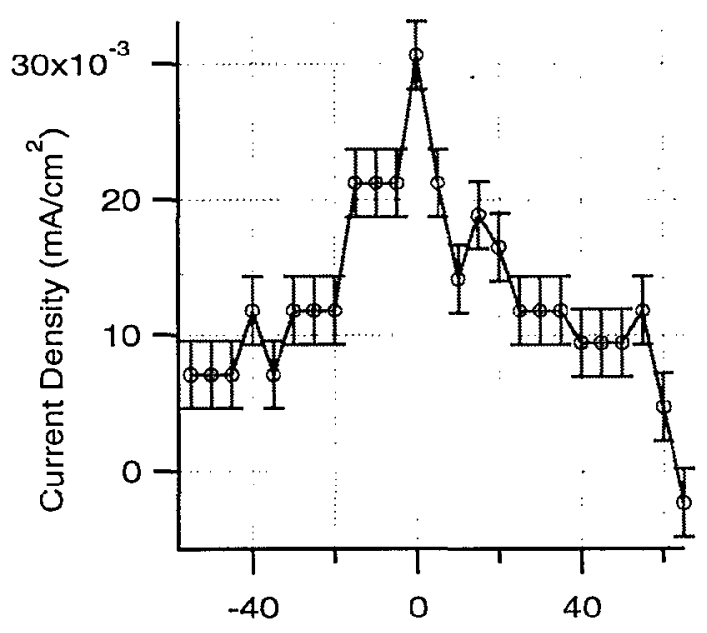

Angle off Thruster Centerline (deg)

Figure 11. Faraday probe data of the ambient plasma wake with probe facing away from thruster at $1.0 \mathrm{~m}$ radius from thruster exit plane. 
Heat Flux Probe. Both radiant and total heat flux was measured at $1.0 \mathrm{~m}$ radius from the thruster in the positive (cathode side) half plane from centerline to $60 \mathrm{deg}$ at $5 \mathrm{deg}$. increments. This data is shown as Figure 12.

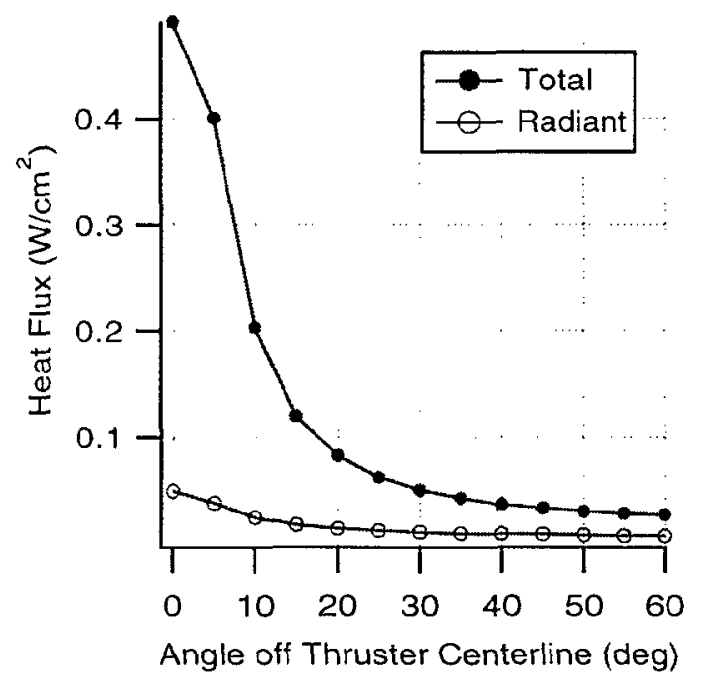

Figure 12. Total and Radiant heat flux at $1.0 \mathrm{~m}$ radius from thruster exit.

NPF Probe. Data with the NPF probe was obtained for the negative half plane from -60 deg to 0 deg from thruster centerline at $1.0 \mathrm{~m}$ radius from thruster exit. This data is shown as Figure 13.

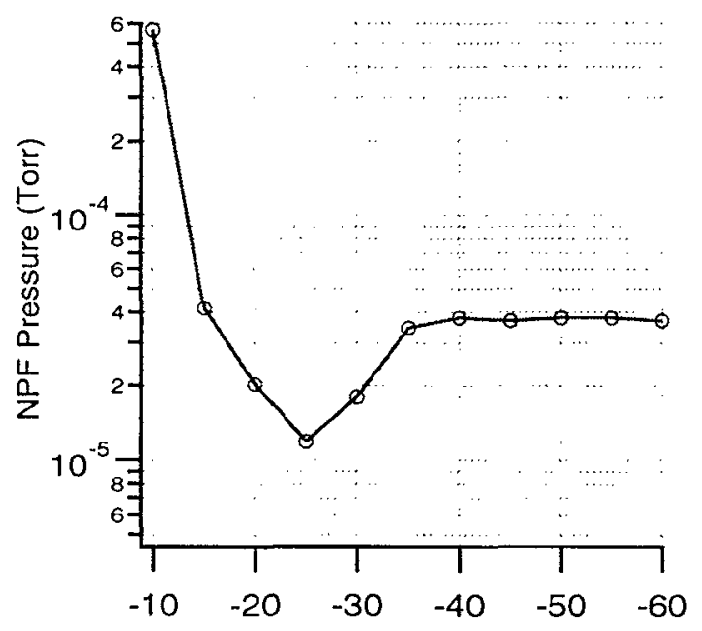

Angle off Thruster Centerline (deg)

Figure 13. NPF probe data at $1.0 \mathrm{~m}$ radius from thruster exit plane.

\section{Analysis of Results}

This section presents an analysis of plasma properties derived from the combined experimental data.

$0.5 \mathrm{~m}$ Radius Data. As shown in equation (2) the ion energy distribution function is directly proportional to the negative derivative of the $I(V)$ vs $V$ data. By differentiating the data numerically a plot of the non-normalized ion energy distribution function can be constructed. However, before this is performed a discrete correction must be made to the raw data.

The first grid and body of the RPA were allowed to float. Although this permits minimal disturbance to the plasma, this floating potential is still slightly lower than the plasma potential. Therefore the small energy shift to the ions induced by the difference between floating potential and plasma potential must be accounted for in the data. In a parallel experiment, Marrese ${ }^{6}$ obtained values of plasma potential at $0.5 \mathrm{~m}$ radius from the thruster at angles of $-60,-45,-$ $30,-15$, and 0 deg off thruster centerline by means of an emissive probe. This data was linearly interpolated to estimate plasma potential at intermediate points. Combining Marrese's interpolated data with RPA floating potential measurements obtained in this investigation, this small shift was accounted for. The magnitude of this shift was between 2 and 5 volts for all points.

The corrected ion energy distributions are shown in Figures 14. The $y$-axis scales for each trace in Figure 14a are not the same; they have been adjusted to highlight the qualitative trends as a function of ion energy.

If it is assumed that the ion component of the plasma is composed entirely of $\mathrm{Xe}^{+}$ions these energy distribution curves can be converted to velocity distribution functions. By evaluating the moments of these distribution functions further insight into the macroscopic transport properties of the plasma can be obtained. 


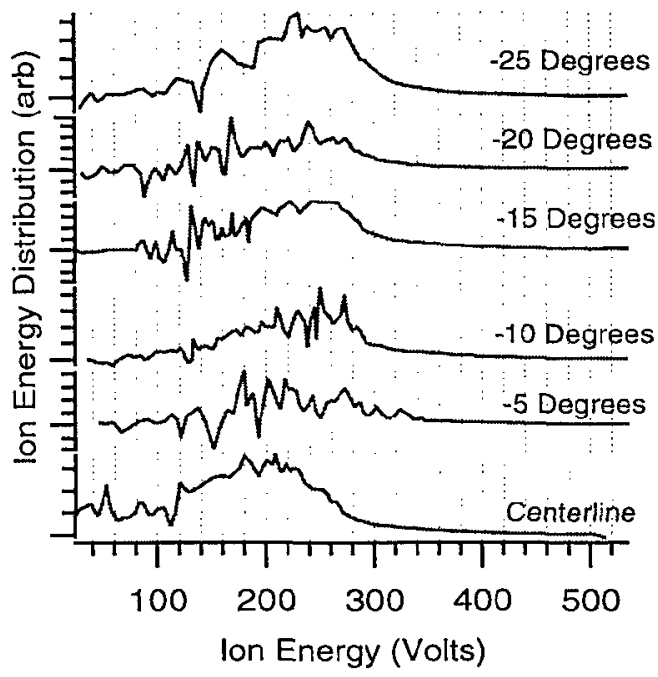

Figure 14a. Ion energy distribution curves at 0.5 $\mathrm{m}$ radius from thruster exit for points $-25,-20$, $15,-10,-5$, and 0 deg off thruster centerline. Scales on y-axis are arbitrary.

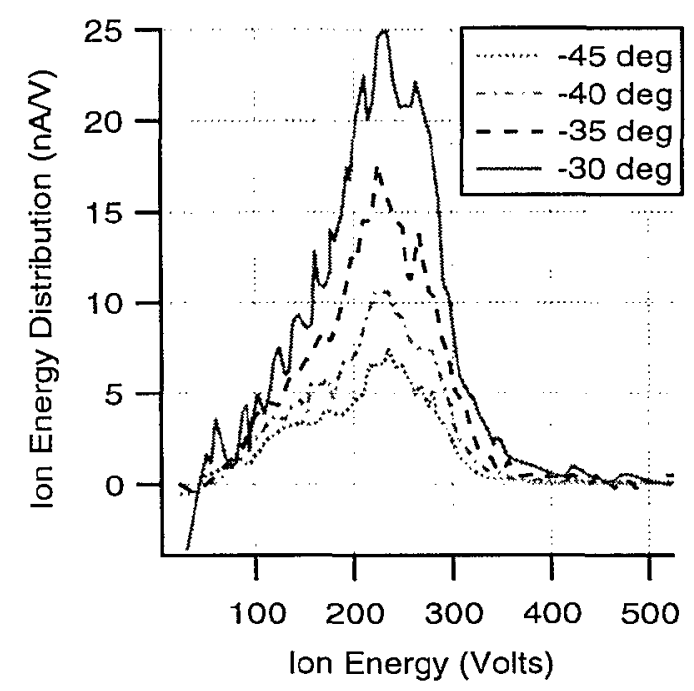

Figure 14b. Ion energy distribution curves at $0.5 \mathrm{~m}$ radius from thruster exit for points -45 , $40,-35$, and -30 deg off thruster centerline.

By evaluating the first moment of the distribution function it is possible to calculate the average ion velocity. A plot of this RPA derived quantity is shown as Figure 15.

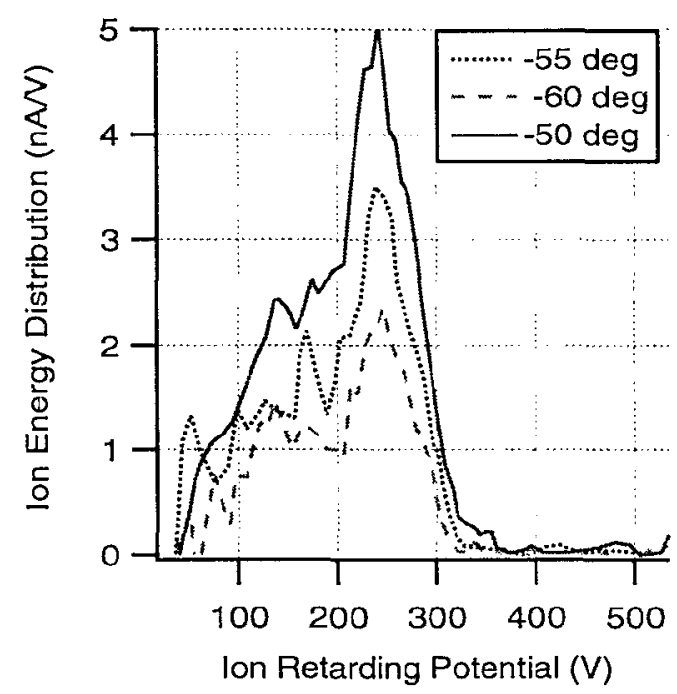

Figure 14c. Ion energy distribution curves at $0.5 \mathrm{~m}$ radius from thruster exit for points -55 , 50 , and $-60 \mathrm{deg}$ off thruster centerline.

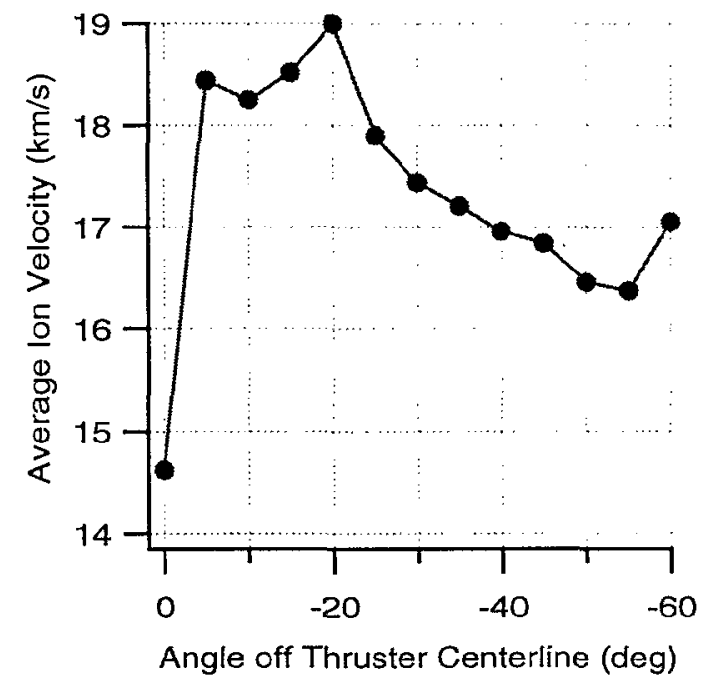

Figure 15. Average ion velocity as computed from the first moment of the RPA-derived distribution function at $0.5 \mathrm{~m}$ radius from thruster exit.

The plume current density and the first moment of the ion velocity distribution function are linked by the ion number density as shown in equation (3) and (4). By subtracting the wake-measured background current density from the direct plumemeasured current density a value for thrusterinduced current density is obtained. Using this net current density along with the RPA- 
derived first moment of the ion velocity distribution function, equation (5) can be used to predict ion density.

Similarly the convective heat flux is linked by the first and the third moments of the ion velocity distribution to the ion number density as shown in equation (7). The convective heat flux can be calculated as the difference between the measured total heat flux and the measured radiant heat flux. Substituting this measured convective heat flux along with the RPA-derived first and third moments of the ion velocity distribution function into equation (7) it is possible to obtain a prediction of ion number density.

According to the methods outlined above, it is possible to compute two separate predictions of ion density. The result of such a computation is shown as Figure 16. This plot compares the ion density predicted by the Faraday probe/RPA distributions with the density predicted by the heat flux probe/RPA distributions.

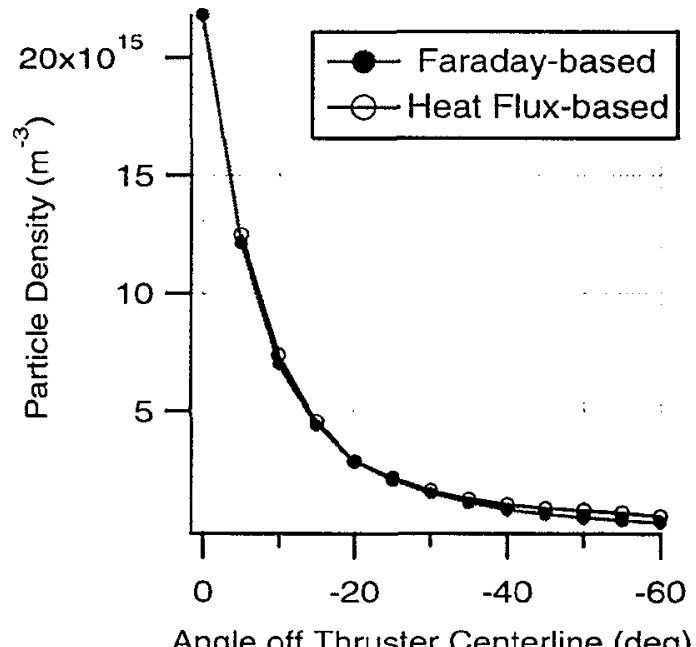

Figure 16. Separate predictions of ion density at $0.5 \mathrm{~m}$ radius from thruster exit based on Faraday probe/RPA data and heat flux probe/RPA data.

It is clear from Figure 16 that both the heat flux probe and the Faraday probe show excellent agreement, predicting nearly identical ion densities. Close inspection, however, reveals that the heat flux probe- derived density is slightly higher than the Faraday probe derived density at almost every point. As was stated earlier, it is important to note that the Faraday probe relies on charge carrying particles for detection and is therefore sensitive only to ions. The heat flux probe, however, relies only on energy deposition to a surface. This method is sensitive to any energy carrying particle regardless of electric charge. The heat flux data, then, reflects both ion and neutral particle heating.

With this in mind, it is possible to calculate the convective heating due to neutral particles. Using the Faraday probederived ion density, along with the RPAderived moments of the ion velocity distribution function, the value of ion convective heating was calculated from equation (7). The difference between the calculated ion convective heating and the measured convective heating will then yield the neutral particle convective heating; this value is shown in Figure 17 compared with the neutral particle flux calculated from the NPF data using equation (10). It is apparent that the trends in the calculated third moment of the neutral particle distribution function (convective heating) closely match the trends in the measured first moment of the neutral particle distribution function (particle flux).

$1.0 \mathrm{~m}$ Radius Data. The data sets at $1.0 \mathrm{~m}$ radius from thruster exit are not as complete as those at $0.5 \mathrm{~m}$ due to equipment complications during testing. However, much knowledge can still be gained from the available data.

Plasma potential data was not available for the data set $1.0 \mathrm{~m}$ from thruster exit. Because of this, it was not possible to calculate the induced energy offset due to the difference between plasma potential and RPA floating potential. However, it was shown in the $0.5 \mathrm{~m}$ data set that this shift was always less than 5 volts. With this in mind, the RPA-derived ion energy distribution curves can still be calculated albeit with a 5 volt uncertainty. This amounts to about a $2 \%$ error at the most 
probable ion energy. The uncorrected ion energy distribution curves are shown in Figure 18.

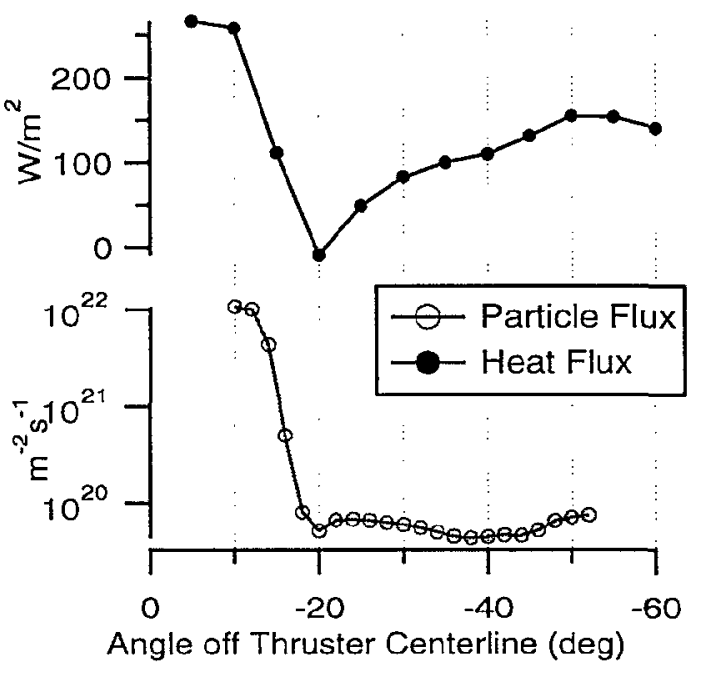

Figure 17. Comparison between NPFmeasured neutral particle flux and calculated neutral particle convective heating at $0.5 \mathrm{~m}$ radius from thruster.

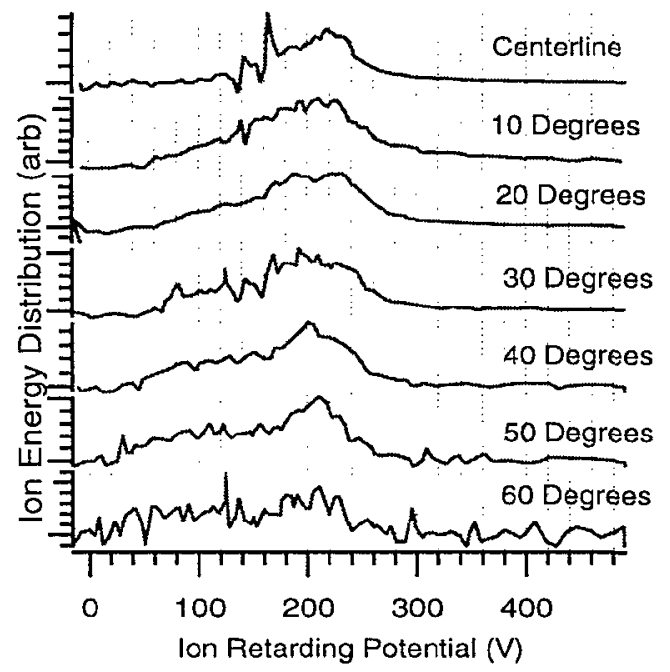

Figure 18. RPA-derived ion energy distribution functions at $1.0 \mathrm{~m}$ radius from thruster exit plane.

Using the calculated ion energy distributions and again assuming the flow to consist only of $\mathrm{Xe}^{+}$particles, it is possible to compute moments of the ion velocity distribution function. Figure 19 shows the computed values of average ion velocity at $1.0 \mathrm{~m}$ radius from thruster exit.

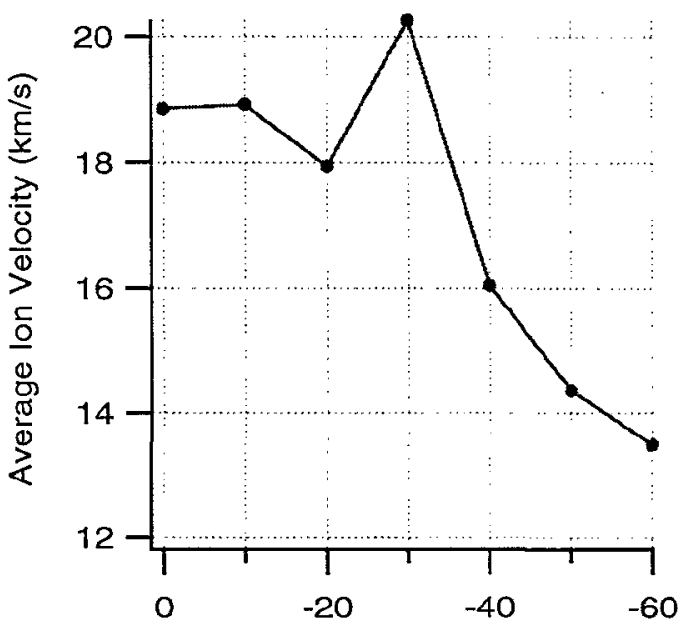

Angle off Thruster Centerline (deg)

Figure 19. Average ion velocity as computed from the first moment of the RPA-derived distribution function at $1.0 \mathrm{~m}$ from thruster exit.

By using equation (10) the NPF probe measured pressure can be converted to neutral particle flux. This first moment of the neutral particle distribution function is shown as Figure 20.

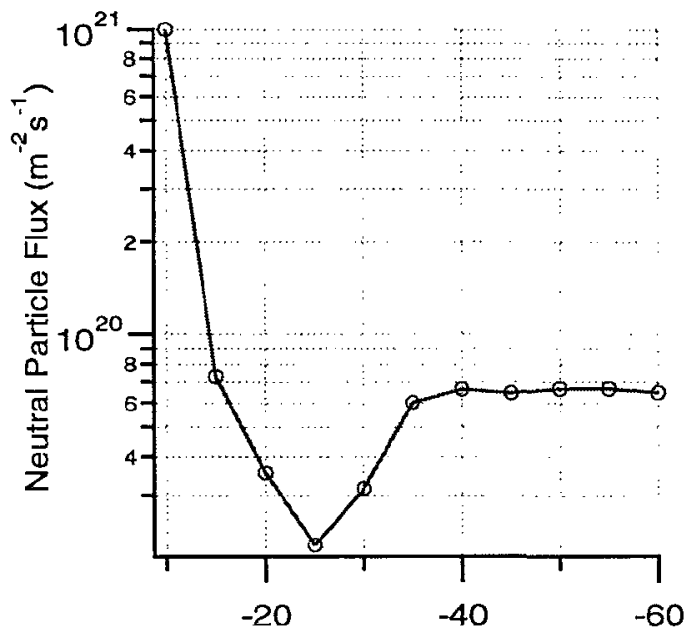

Angle off Thruster Centerline (deg)

Figure 20. Neutral particle flux measurements at $1.0 \mathrm{~m}$ radius from thruster exit. 


\section{Discussion}

Distribution of Ion Energy. One of the most striking results of this investigation was the discovery of a high energy annulus surrounding a low energy core in the plume at $0.5 \mathrm{~m}$ radius from thruster exit (see Figure 15). Although such a topology would be expected in the near field of the thruster due to the annular shape of the discharge chamber, it was believed that the divergence of the ion beam would smear out this configuration very rapidly. On the contrary, the average ion velocity on centerline at $0.5 \mathrm{~m}$ is less than the velocity computed for any other point measured in the $0.5 \mathrm{~m}$ data set. This low energy core is very narrow, limited to a region in space with a half angle of $5 \mathrm{deg}$. It should be noted, however, that this annulus is not manifested by a corresponding trend in ion current density. The ion density increases toward centerline at a much larger rate than the ion velocity shift; consequently plasma density measurements as well as current density measurements will fail to uncover this annulus/core configuration.

The average ion velocity data at $1.0 \mathrm{~m}$ shows a similar trend (Figure 19). Although the low energy core has been essentially filled in by the diverging ion beam, the high energy annulus is still apparent at a slightly greater angle off centerline ( $30 \mathrm{deg})$.

A discrepancy seems to arise when comparing the average ion velocity values shown for $1.0 \mathrm{~m}$ compared with those at $0.5 \mathrm{~m}$ : the velocity for the peak of the high energy annulus at $1.0 \mathrm{~m}$ is actually greater than the peak at $0.5 \mathrm{~m}$. The reason for this stems from the lack of energy correction data in the $1.0 \mathrm{~m}$ data set. The $0.5 \mathrm{~m}$ data has been corrected for the energy shift imposed due to the difference between RPA floating potential and plasma potential, while the data at $1.0 \mathrm{~m}$ is still uncorrected for this energy addition. This small energy correction can have substantial effect on computed velocity.

The existence of a high energy plasma annulus with low spatial divergence is consistent with thruster discharge chamber geometry and field topology. The higher energy ions are formed further back inside the discharge chamber. These ions, in order to escape the discharge chamber without colliding with the wall, must have their velocity vectors contained within a defined solid angle. Those ions formed near the end of the discharge chamber will have lower energy as a consequence of the field topology, and will also have their velocity vectors distributed about a larger solid angle.

The low energy core is due to the distribution of ion production within the discharge chamber. According to Bishaev and $\mathrm{Kim}^{7}$ the majority of the ionization within the thruster occurs very near the inner wall of the discharge chamber. In order for these ions to escape the discharge chamber without colliding with a wall and being lost, their velocity vectors must be directed largely away from thruster centerline. Such a distribution of velocity vectors would produce a depletion of high energy ions an thruster centerline until a considerable distance downstream. Such a scenario is depicted in Figure 21.

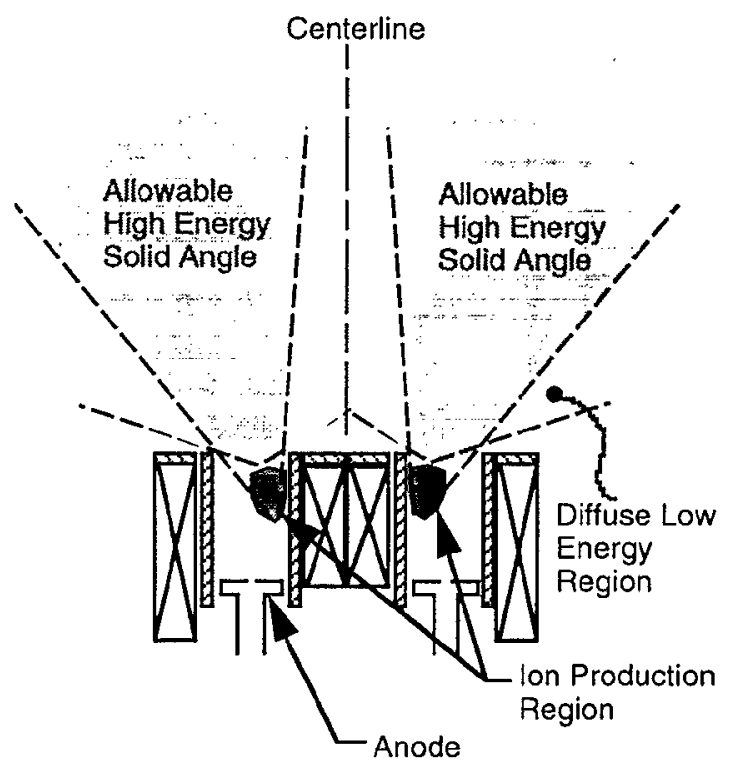

Figure 21. Schematic representation of mechanism causing high energy annulus and low energy core in thruster plume. Ion production region denoted as according to Bishaev and Kim. ${ }^{7}$ High energy ions are formed closest to anode. 
Charge Exchange Processes. Another striking feature revealed within the plume structure is the distribution of neutral particles. Although Figure 16 shows that both the Faraday probe and the heat flux probe predict almost identical ion densities, there is a small discrepancy between the curves. Initially the discrepancy seems to be so small that one would tend to dismiss it as a numerical artifact or experimental error. However, when the calculated difference between the two densities in the form of neutral particle heating is compared with the data from the NPF probe (Figure 17), it is seen that the trends agree almost exactly. This agreement between two separate techniques of determining neutral particle properties strongly suggests that the effect is physically based.

The neutral particle velocity distribution function, which is necessary for a complete understanding of the neutral flow, is absent from these measurements. However considerable knowledge of the neutral component can be derived from available quantities. From a top level perspective, it would be valuable to know whether these neutrals are "slow" background particles, or "fast" CEX particles. If we assume that the neutrals are slow, macroscopically stagnant Maxwellian particles at temperature $T_{0}$ then the free molecular convective heating to the water cooled probe is computed as

$$
\mathrm{q}_{\mathrm{conv}}=\frac{1}{4} \mathrm{n}_{0} \overline{\mathrm{v}}_{0} \mathrm{k}\left(\mathrm{T}_{0}-\mathrm{T}_{\mathrm{p}}\right)
$$

Since the flow is stagnant, the pressure measured by the NPF probe would be the true ambient neutral pressure; this could be converted via the ideal gas law to obtain no. Evaluating equation (11) for the sample point at -14 deg from centerline at $0.5 \mathrm{~m}$ where $\mathrm{P}_{0}=2.5 \times 10^{-3}$ torr, and assuming a neutral temperature of $300 \mathrm{~K}$, yields a value of neutral particle convective heating of 2 $\mathrm{W} / \mathrm{m}^{2}$. This is much lower than the measured value of $150 \mathrm{~W} / \mathrm{m}^{2}$ for the neutral heating at this location. Furthermore, in order for a slow Maxwellian population of neutrals to account for this heating, the neutrals would have to have a temperature of $1,500 \mathrm{~K}$ at this sample point. Such a high temperature is highly improbable. It is therefore apparent that a distribution of slow neutrals can not account for the measured neutral convective heating.

Assuming then that the neutrals are fast products of CEX it is possible to calculate estimates of their velocity and density. The neutral particle flux, $n_{n}<u_{n}>$, was measured directly using the NPF probe. The product of neutral density and third moment of the neutral velocity distribution function can be calculated using equation (7):

$$
n_{n}\left\langle u_{n}^{3}\right\rangle=\frac{2 q_{\text {conv }}+4 k T_{p} n_{n}\left\langle u_{n}\right\rangle}{m_{n}} .
$$

In equation (11) qconv is the neutral particle heating calculated as in Figure 17, $\mathrm{T}_{\mathrm{p}}$ is the temperature of the heat flux sensor, and $n_{n}<u_{n}>$ is obtained from the NPF data.

Thus, one has values of both $n_{n}<u_{n}>$, and $n_{n}\left\langle u_{n}{ }^{3}>;\right.$ this represents two equations in three unknowns, $n_{n}\left\langle u_{n}\right\rangle$, and $\left\langle u_{n}{ }^{3}\right\rangle$. Since we have assumed that the neutrals are fast, it is equivalent to assume that the bulk velocity of the neutral particles is much greater than the average thermal velocity. Under this hypersonic, or high speed ratio assumption the number of unknowns can be reduced by one. Specifically, for a very large speed ratio velocity distribution with bulk flow velocity $u_{n}$,

$$
\begin{gathered}
\langle u\rangle \approx u_{n} \\
\text { and } \\
\left\langle u^{3}\right\rangle \approx u_{n}^{3} .
\end{gathered}
$$

We now have two equations in two unknowns, $\mathrm{r}_{\mathrm{n}}$ and $\mathrm{u}_{\mathrm{n}}$. Solving for these quantities provides an estimate of neutral particle velocity and density. This calculation is shown as Figure 22. 


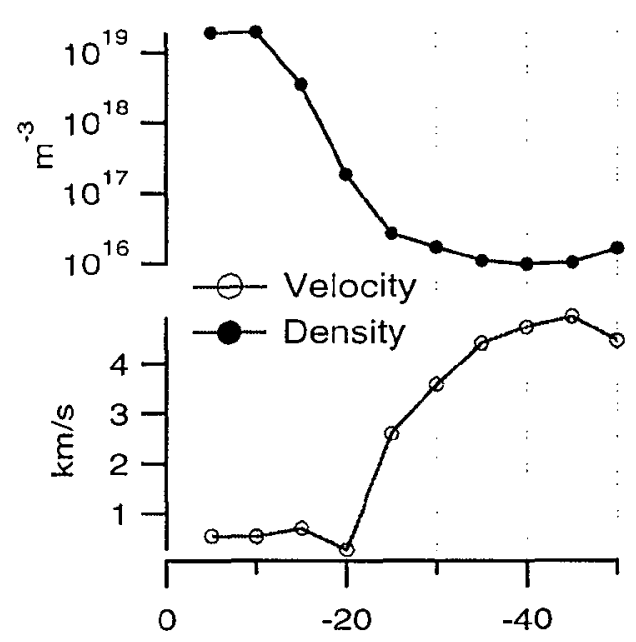

Angle off Thruster Centerline (deg)

Figure 22. Estimates of fast CEX neutral particle density and velocity at 0.5 radius from thruster exit plane.

Figure 22 shows expected trends in both velocity and density. The estimated neutral velocity increases with angle off thruster centerline. As was shown in Figure 21, the high energy ions will tend to have velocity vectors aimed away from centerline. These high energy ions would account for the high energy neutrals found within the same location. Although one might expect to see a peak in neutral particle velocity that corresponds to the peak in ion velocity, this trend does not show up in Figure 22. This is believed to stem from the randomization of direction inherent to CEX collisions. The ion velocity peak was only about $5 \%$ larger than the neighboring points. Since the velocity of the CEX neutral does not maintain the same direction as that of the parent ion, this small peak would be spread out amongst the three random velocity components of the CEX neutrals. The overall trend in ion velocity, that of low velocity on centerline increasing off centerline, is reflected in the neutral data. The distribution of neutral density is also consistent with a CEX description, as will be discussed next.

As was stated in the Background section, there are two methods for evaluating CEX: one can either look for the fast neutrals, as was done for Figure 22, or the slow ions, since the rate of production is one-to-one. The CEX-produced slow ions were evaluated by turning the Faraday probe backwards in the plume and sampling the ambient plasma, as shown in Figure 7. Before discussing the CEX data represented in Figures 7 and 22, it is instructive to consider the process by which CEX pairs are produced. by

The rate of CEX pair production is given

Equation [13]

$$
N_{i, 0}=n_{i} n_{0} \iiint_{\infty} d^{3} u_{i} \iiint_{\infty} d^{3} u_{0} \sigma_{c}(g) g f_{i}\left(u_{i}\right) f_{0}\left(u_{0}\right)
$$

where $\mathrm{N}_{i, 0}$ is the number of CEX ion-neutral pairs produced per unit time per unit volume, $\mathrm{g}$ is the relative interparticle speed, and $\sigma_{\mathrm{C}}$ is the total cross section for $\mathrm{Xe}^{+} \mathrm{X}_{\mathrm{e}}$ charge exchange. Quantities with a subscript i denote fast plume ion quantities while the subscript 0 denotes slow, ambient neutral properties. It is important to note the distinction between the subscript 0 and the subscript $n$, used previously: $n$ denotes properties of CEX-produced fast neutrals, while 0 denotes slow ambient "target" neutrals.

Equation (13) can be simplified if it is assumed that the ion velocity is much greater than the ambient neutral thermal speed. In this approximation

$$
g=\left|\mathbf{u}_{\mathrm{i}}-\mathbf{u}_{0}\right| \approx \mathrm{u}_{\mathrm{i}} .
$$

Furthermore, the cross section for CEX, $\sigma_{\mathrm{C}}$, remains almost constant over the energy range of interest for this case. ${ }^{8}$ Under these approximations,

$$
\begin{aligned}
N_{i, 0} & =\sigma_{c} n_{i} n_{0} \iiint_{\infty} d^{3} u_{i} u_{i} f_{i}\left(u_{i}\right) \iiint_{\infty} d^{3} u_{0} f_{0}\left(u_{0}\right) \\
& =\sigma_{c} n_{i} n_{0}\left\langle u_{i}\right\rangle .
\end{aligned}
$$

$$
\text { or, equivalently }
$$

$$
N_{i, 0}=\sigma_{c} n_{0} \frac{J_{i}}{e}
$$


Equation (14) tells us that the number of CEX-produced pairs of fast neutrals and slow ions is directly proportional to the product of ambient neutral density and thruster ion current density. Assuming a constant background neutral target density, the rate of CEX production is directly proportional to the Faraday probe-measured current density.

The behavior described by equation (14) is readily apparent in Figure 7 . The slow CEX ion spatial distribution, as measured by the Faraday wake current flux, has a nearly identical shape to the thruster beam ion current density. Similarly, the plot of fast neutral density shown as Figure 22 also shows a distribution of CEX-produced neutrals with the same spatial distribution as the thruster beam ion current density.

In addition to shedding light on the CEX process, the wake-measured ion current density reveals another property of the plume structure. It can be seen from Figure 7 that the wake current flux is asymmetric; the flux is slightly larger for positive angles off centerline, corresponding to the location of the thruster cathode. It appears that the ambient plasma density is slightly greater an the cathode side. Although the asymmetry is slight, this behavior was very repeatable throughout testing and is believed to be physically based. This asymmetry does not show up in a traditional Faraday probe sweep; when the probe collector is facing into the plume the signal from the beam ions is much larger than the background signal and obscures this density distribution.

Current Density Distribution. In recent investigations of SPT-100 plume current density a recurring inconsistency has been identified. By assuming an axisymmetric plume, it is possible to integrate the current density over space. The resulting value of current should be identical to the thruster discharge current. However, when this operation is performed the resulting integrated current is higher than the actual discharge current. This behavior was believed to stem from the ambient CEXinduced ions in the facility. For example, simply using the current density at $0.5 \mathrm{~m}$ as measured with the Faraday probe facing the plume produces an integrated total current of $5.42 \mathrm{~A}$, while the discharge current was only $4.5 \mathrm{~A}$. This represents a $20 \%$ error. By turning the probe around and measuring the stray CEX current this investigation hoped to alleve this inconsistency. However, the measured ambient current density was much lower than expected. Even when subtracting this background current from the plume current the total integrated beam current is still 5.12A. While this is an improvement in error, the phenomena responsible for this high current does not appear to be stray CEX ions. The most plausible explanation for this would seem to be the production of secondary electrons from the probe collector surface caused by ion impact. Although the collector was coated with tungsten to minimize this effect, the data suggests that secondary electron emission remains a source of error.

The $1.0 \mathrm{~m}$ radius data set is missing one vital piece of information: the directed ion current density. Without this data the comprehensive analysis carried out for the $0.5 \mathrm{~m}$ data was not possible. However, all of the trends displayed in the available data at $1.0 \mathrm{~m}$ are consistent with those at $0.5 \mathrm{~m}$ : namely the high energy ionic annulus accompanied by a corresponding dip in neutral particle flux at the same location (compare Figures 19 and 20). Although the narrow low energy ionic core is not present in the $1.0 \mathrm{~m}$ data, this is consistent with a slowly diverging ion beam as shown in Figure 21; this beam would eventually fill in the low energy core with high energy ions, as is shown in the data.

\section{Conclusion}

By making comprehensive measurements of related ion and neutral particle properties within the plume it was possible to gain insight into plume structure and thruster operation. The phenomena included ionneutral charge exchange, spatial distribution of ion energy within the plume, and information regarding beam and ambient plasma properties. 
Analysis revealed that the plume possesses a high energy annulus surrounding a very narrow low energy core at $0.5 \mathrm{~m}$ radius from the thruster. This core is still incompletely filled in by beam divergence at $1.0 \mathrm{~m}$. This structure is consistent with thruster discharge chamber geometry, field topology, and distribution of ion production.

Through the use of a new probe design coupled with heat flux measurements, it was possible to derive information regarding neutral particle properties within the plume. The data analysis suggests that these neutral particles are the high energy products of ionneutral CEX collisions. As predicted by theory, the density of fast neutrals corresponds directly with the density of fast ions.

\section{Acknowledgments}

The research reported herein was sponsored by the Air Force Office of Scientific Research; this support is gratefully acknowledged. The authors would also like to thank Mr. Mike Day for loan of SPT-100 and PPU, machinist Terry Larrow, and the PEPL staff.

\section{References}

[1] King, L.B., and Gallimore, A.D., "A Gridded Retarding Pressure Sensor for Ion and Neutral Particle Analysis in Flowing Plasmas," AlAA-96-2983, Joint Propulsion Conference, July 1-3, 1996, Orlando, FL.

[2] Hutchinson, I.H, Principles of Plasma Diagnostics, Cambridge University Press, 1987.

[3] Marrese, C.M, Gallimore, A.D., Haas, J., Foster, J.E., King, L.B., and Kim, S.W., "An Investigation of Stationary Plasma Thruster Performance with Krypton Propellant," AIAA-95-2932, Joint Propulsion Conference, July 10-12, 1995 , San Diego, CA.
[4] Gallimore, A.D., Kim, S.W., Foster, J.E., King, L.B., and Gulczinski III, F.S., "Near and Far-field Plume Studies of a $1 \mathrm{~kW}$ Arcjet," Journal of Propulsion and Power, Vol 12, No. 1, Jan-Feb 96, pp. 105-11.

[5] Myers, R.M, and Manzella, D.H., "Stationary Plasma Thruster Plume Charateristics," IEPC-93-096, Proc. of 23rd Int'l Electric Propulsion Conference, Vol. 2, 893-912.

[6] Marrese, C.M, and Haas, J., unpublished investigation, Department of Aerospace Engineering, University of Michigan.

[7] Bishaev, A.M, and Kim, V., "Local Plasma Properties in a Hall-current Accelerator with an Extended Acceleration Zone," Sov. Phys. Tech. Phys. 23(9), Sept. 1978, pp. 1055-57.

[8] Massey and Gilbody, Electronic and Ionic Impact Phenomena, Vol. IV, Oxford University Press, 1974. 